\title{
Ti6Al4V ALAȘIMININ TALAȘLI İMALATI SIRASINDA TERMAL KAMERA İLE SICAKLIK ÖLÇÜMÜ VE SONLU ELEMANLARLA MODELLENMESİ
}

\author{
Umut KARAGÜZEL*
}

Işık Üniversitesi, Mühendislik Fakültesi, Makine Mühendisliği Bölümü, İstanbul, Türkiye

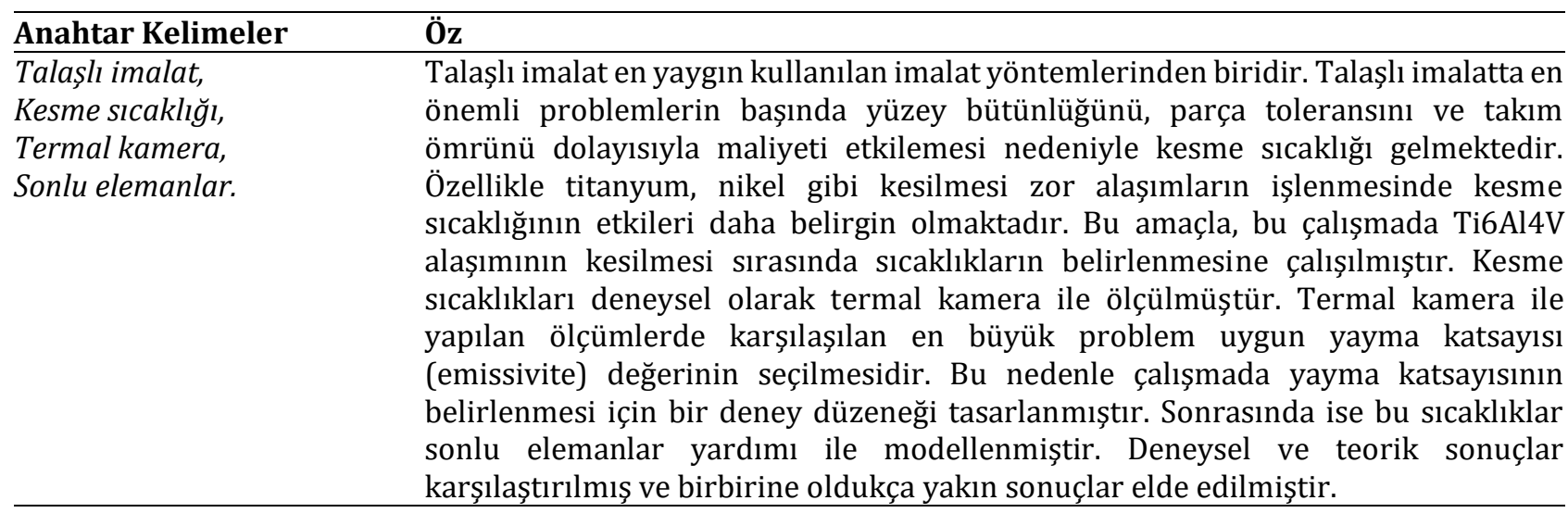

\section{CUTTING TEMPERATURE MEASUREMENT BY THERMAL CAMERA AND FINITE ELEMENT MODELING DURING MACHINING OF TÍ6AI4V ALLOY}

\author{
Keywords \\ Machining, \\ Cutting temperature, \\ Thermal camera, \\ Finite element model.
}

\begin{abstract}
Machining, or metal cutting, is one of the most common manufacturing processes. Cutting temperature can be stated as one of the most important problems in machining due to its effects on the machined part surface integrity, part tolerances and the tool wear so on the manufacturing cost. In this study, the cutting temperatures are determined during machining of Ti6Al4V titanium alloy. Cutting temperatures were measured by a thermal imaging system in which the most important problem is choosing the right emissivity value of the measured surface. Hence, an experimental setup was designed and the emissivity value of Ti alloy was determined. Then, the cutting temperatures were predicted by developed finite element model. The experimental and theoretical results were compared and a very good match was achieved.
\end{abstract}

\section{Alıntı / Cite}

Karagüzel, U., (2019). Ti6Al4V Alaşımının Talaşlı İmalatı Sırasında Termal Kamera İle Sıcaklık Ölçümü Ve Sonlu Elemanlarla Modellenmesi, Mühendislik Bilimleri ve Tasarım Dergisi, 7 (2), 265-271.

Yazar Kimliği / Author ID (ORCID Number) $\quad$ Makale Süreci / Article Process

U. Karagüzel, 0000-0001-5178-7614

\begin{tabular}{|l|l|}
\hline Makale Süreci / Article Process \\
\hline Başvuru Tarihi / Submission Date & 18.06 .2018 \\
Revizyon Tarihi / Revision Date & 27.10 .2018 \\
Kabul Tarihi / Accepted Date & 31.12 .2018 \\
Yayım Tarihi / Published Date & 26.06 .2019 \\
\hline
\end{tabular}

\section{Giriş}

Talaşlı imalat muhtelemen metal ve alaşımların üretilmesinde ve onlara son şeklinin verilmesinde en çok kullanılan yöntemdir. Bu nedenle de birçok araştırmacının ilgisini çekmektedir. Bu araştırmaların en temelindeki hedef talaş kaldırma hızının arttırılması ve tabii üretim maliyetlerinin düşürülmesidir (Da Silva ve Wallbank, 1999). Bu hedeflerin gerçekleştirilmesi için süreç sırasında karşılaşılan kimi problemlerin aşılması gerekmektedir. Talaşlı imalatta bu problemlerin başında kesme sıcaklı̆̆ı gelmektedir.

\footnotetext{
* ilgili yazar / Corresponding author: umut.karaguzel@isikun.edu.tr, +90-216-528 7263
} 
Talaşlı imalatta harcanan gücün neredeyse tamamı ısıya dönüşmektedir (Abukhshim vd., 2006). Ortaya çıkan bu ısının bir kısmı işparçasına geçerken diğer bir kısmı takıma, bir diğer kısmı ise talaşa geçer. Geçen bu ısıyla birlikte sıcaklıkların artması parçada faz değişimine ve yüzey bütünlüğünün bozulmasına, parçanın ısıl genleşmeler nedeniyle tolerans dışına çıkmasına ve takımın aşınmasına neden olur. Sonuç olarak, kesme sırasında ortaya çıkan sıcaklıkların belirlenmesi sürecin optimizasyonu açısından oldukça önemlidir.

Yukarıda da bahsedildiği üzere talaşlı imalat işleminde enerjinin büyük bir bölümü ısıya dönüşmektedir. Hatta Trent ve Wright (2000) bu oranın \%99 olduğunu ileri sürmektedirler. Oluşan bu ısının Şekil 1' de gösterilen 3 adet kaynağı bulunmaktadır; kayma düzleminde meydana gelen plastik deformasyon (Birinci deformasyon bölgesi), talaş yüzeyinde meydana gelen takım ve talaşın sürtünmesi (ikinci deformasyon bölgesi) ve yeni oluşturulmuş yüzeyde takımın işparçasına sürtünmesi (üçüncü deformasyon bölgesi). Tüm bunlar işparçası ve takımda sıcaklıkların artışına neden olur (Longbottom ve Lanham, 2005).

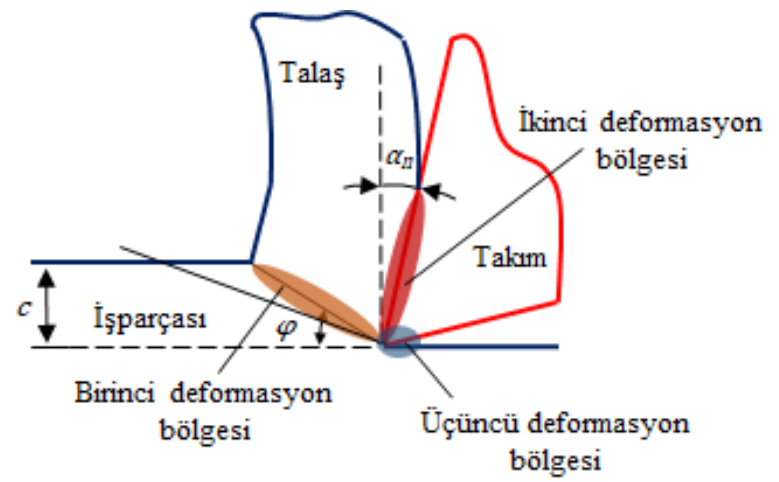

Şekil 1. Talaşlı imalatta talaş ve ısı oluşumu

Talaşlı imalatta kesme sıcaklığının belirlenmesi oldukça önemlidir ancak bir o kadar da zordur. Bunun nedenleri; kesme işleminin oldukça küçük bir anlanda gerçekleşmesi, sıcaklık gradyanlarının çok yüksek oluşu, sistemin hızlı oluşu ve oluşan talaşın kesme bölgesine erișebilmesini zorlaștırması olarak verilebilir (Shaw ve Cookson, 1984). Buna rağmen araştırmacılar kesme sıcaklığının belirlenmesi için çeşitli deneysel ve teorik çalışmalar gerçekleștirmişlerdir.

Kesme sıcaklığının ölçülmesi için geliştirilen yöntemlerin belki de en eskisi kalorimetrik metotdur. $\mathrm{Bu}$ yöntemde işlem suya gömülü bir şekilde gerçekleştirilmektedir ve işlemin suyun sıcaklığını ne kadar arttırdığı ölçülmektedir. Ancak bu işlem pek de pratik bir yöntem değildir. En iyi oturmuş yöntemlerden biri takım-işparçası ısılçifti yöntemidir. Takım ve işparçası kesme sırasında temas halindeyken bir sıcak temas noktası oluştururlar bu da işlem sırasında bir emf (elektromotor kuvvet) üretilmesine neden olur ve bu emf değeri sıcaklıkla değişir. Bu değer kalibre edildiği takdirde o takım ve o işparçası malzeme çifti için bir sıcaklık ölçme sistemi geliștirilmiș olur. Diğer bir yöntem gömülü termoeleman yöntemidir. Termoeleman takım veya işpçarçasına açlan küçük bir deliğin içine yerleştirilerek noktasal ölçüm yapılması sağlanır. Son olarak talaşlı imalat sırasında termal kameraların kullanımı ise görece yeni bir yöntem dir. Bu yöntemde en büyük problem kameranın uygun bir açıda yerleştirilmesi ve uygun yayma katsayısı değerinin belirlenmesidir.

Deneysel yöntemlerin yanı sıra ortaya çıan sıcaklıkların belirlenmesinde teorik yöntemlerden de faydalanılır. $\mathrm{Bu}$ yöntemler analitik ve sayısal yöntemler olmak üzere iki büyük başlıkta toplanabilir. Analitik yöntemlerin avantajı; işlemin fiziksel altyapısına dair daha çok bilgi vermesi ve hızl olmasıdır; ancak her geometri için analitik çözüm yoktur bu nedenle problemin basitleştirilmesi gerekmektedir. Sonlu elemanlar veya sonlu farklar gibi sayısal yöntemler ise analitik yöntemlere göre yavaş olmakla beraber bilgisayar teknolojisinin gelişmesi ile birlikte daha çok ön plana çıkmışlardır. $\mathrm{Bu}$ yöntemlerle çok karmaşık problemler bile modellenebilir.

$\mathrm{Bu}$ çalışmada Ti6Al4V alaşımının tornalanması sırasında ortaya çıkan kesme sıcaklıkları hem deneysel hem de teorik olarak incelenmiştir. $\mathrm{Bu}$ amaçla termal kamera ile kesme sıcaklıkları ölçülmüş ve ayrı bir deney düzeneği ile analizlerde kullanılan yayma katsayısı kalibre edilmiştir. Sonrasında da bulunan bu kesme sicaklıkları sonlu elemanlar yöntemi ile modellenmiş ve sonuçlar karşılaştırılmıştır.

\section{Bilimsel Yazın Taraması}

Bu çalıșmada; Ti6Al4V titanyum alașımının talaşlı imalatı sırasında kesme sıcaklıkları ölçülmüş ve sonlu elemanlar yöntemi ile modellenmiștir. Bu kapsamda yapılan bilimsel yazın taraması aşağıda belirtilmiştir.

Stephenson (1993) takım-işparçası ısılçifti yönteminin geliştirilmesinde büyük katkıda bulunmuştur. Bu çalışmalar sırasında bu yöntemle ölçülen emf değerlerinin temas bölgesindeki ortalama değerler olduğu sonucuna varmıșlardır. Stephenson ve Ali (1992) sonrasında bu yöntemi kullanarak üzerinde oyuklar bulunan bir parçayı tornalayarak kesintili kesme durumunda sıcaklıkları ölçmüşlerdir. Deneyler sırasında gri dökme demir ve aluminyum alaşımı ișparçası olarak kullanılırken, kesici takım olarak ise kaplamasız WC kullanılmıștır. Sonuç olarak kesintili kesme işleminde kesme sıcaklıklarının sürekli temasın olduğu tornalama işlemlerine göre düșük olduğu sonucuna varmıșlardır. Leshock ve Shin (1997) de takım işparçası ısılçift yöntemini kullanarak 
AISI 4140 ve Inconel 718 malzemelerinin karbür takımla işlenmeleri sırasında kesme sıcaklıklarını ölçmüşler ve bunları takım aşınması ile ilişkilendirmişlerdir.

Daha önce de bahsedildiği gibi kesme sıcaklıklarını ölçmek için kullanılan bir diğer yöntem gömülü termoelemanların kullanılmasıdır. Sullivan ve Cotterell (2001) K tipi (kromel-alumel) termoelemanları kullanarak 6082-T6 aluminyum alaşımın tornalanması sırasında kesme sıcaklıklarını ölçmüşlerdir. Bilindiği gibi tornalama sırasında işparçası dönmektedir, araştırmacılar özel bir yöntem geliștirerek termoelemanları parça içine gömmüșler ve kesme sırasında dönmelerine izin vermişlerdir. Sonuç olarak artan kesme hızları ile parça yüzeyindeki sıcaklıkların azaldığını bulmuşlardır. Jiang vd. (2013) de gömülü termolemanları kullanarak AISI 1045 çeliğinin frezelenmesi sırasında hem işparçası hem de takımdan sıcaklık ölçmüşlerdir. Buradaki en ilginç sonuç işparçası sıcaklıkları için kritik bir kesme hızı olduğunu iddia etmeleridir. Bu kritik kesme hızından sonra kesme sıcaklıkları düșmektedir. Bunun nedeni olarak ısı transferi için yeterli zaman bulunmaması olarak göstermişlerdir.

Görece daha yeni bir yöntem olan termal kamera ile ölçüm de ise Davies vd. (2005) çalıșmaları ön plana çıkmaktadır. Davies vd. (2005) AISI 1045 çelik malzemesinin kesilmesi sırasında termal kamera ile birlikte termal mikroskop da kullanmışlardır böylelikle oldukça detaylı deney sonuçları elde etmișlerdir. Armendia vd. (2010) ise yine termal kamera kullanarak frezeleme sırasında Ti6Al4V ve AISI 4140 malzemesinin sıcaklıklarını ölçmüşlerdir. $\mathrm{Bu}$ sayede takımda termal yorulmaya neden olan çevrimsel sıcaklıkları ölçme imkanı bulmușlardır. Ancak bu çalışmalarda yayma katsayısının önemi yeterince tartışılmamıştır.

Deneysel çalışmaların yanısıra literatürde modelleme çalışmaları da yer almaktadır. Bu çalışmaların ilklerinden biri Hahn (1951) tarafından gerçekleştirilmiştir. Hahn (1951), Jaeger (1942) tarafından geliştirilen hareketli ısı kaynağı modelini kullanarak kayma düzlemindeki sicaklıkları hesaplamıştır. Günümüzde ise geliştirilen sonlu elemanlar kodları talaşlı imalatında modellenmesinde gelecek vaat etmektedir. Özel ve Altan (2000) Deform 2D yazılımını kullanarak frezeleme sırasında takımda oluşan gerilmeleri ve sicaklıkları tahmin etmeyi başarmışlardır.

Bu bilgiler ışığında bu çalışmada özellikle havacılık ve medikal sanayinde önemli bir malzeme olan Ti6Al4V'in talaşlı imalatı sırasında kesme sıcaklıklarının ölçülebilmesi için yeni deney düzeneği tasarlanmıştır. Bu deney düzeneği takım tezgahına yerleştirilen bir termal kamerayı da içermektedir. Literatür çalıșmasında da bahsedildiği gibi termal kamera ile ölçümlerde en önemli parametrelerden biri yayma katsayısı değeridir. $\mathrm{Bu}$ nedenle yayma katsayısının sıcaklıkla değişiminin kalibrasyonu için ayrı bir deney düzeneği daha bu çalışmada tasarlanmıștır. Son olarak deneysel olarak elde edilen sıcaklıklar aynı zamanda Deform 2D programında da modellenmiș ve sonuçlar karșılaștırılarak yorumlanmiştır.

\section{Deneysel Çalışma}

Gerçekleștirilen deneysel çalıșma iki aşamadan oluşmaktadır. İlk aşamada kesme sıcaklıklarının termal kamera ile ölçülebilmesi için bir deney düzeneği tasarlanmıș ve çeșitli parametrelerde kesme deneyleri gerçekleștirilmiștir. İkinci aşamada ise termal kamera ile ölçümde önemli bir parametre olan yayma katsayısı değerinin sıcaklıkla değișiminin bulunması amacıyla başka bir deney düzeneği tasarlanmıș ve yayma katsayısı farklı sıcaklıklar için kalibre edilmiştir. Bu değer sonrasında termal kamera yazılımı kullanılarak daha önce gerçekleştirilen deney sonuçlarına aktarılmıştır.

\subsection{Kesme Deneyi ve Sıcaklıkların Ölçümü}

Kesme deneylerinde Tablo 1'de kimyasal bileşimi verilen Ti6Al4V titanyum alașımı kullanılmıștır. Bu alașım özellikle havacılık, uzay ve medikal sektöründe kullanılan öemli bir alașımdır. Ancak Ezugwu ve Wang (1997) 'nin de belirttiği gibi bu alaşımın talaşlı işlenebilirliği iyi değildir ve işlenirken ortaya çıkan yüksek sıcaklıklar nedeniyle hızlı bir takım aşınmasına neden olur. Bu nedenle bu alaşımın işlenmesi sırasında ortaya çıkan sıcaklıkların araştırılması önemlidir.

Tablo 1. Ti6Al4V kimyasal bileșimi

\begin{tabular}{|c|c|c|c|c|c|c|}
\hline $\mathbf{C}$ & $\mathbf{F e}$ & $\mathbf{N}_{\mathbf{2}}$ & $\mathbf{O}_{\mathbf{2}}$ & $\mathbf{A l}$ & $\mathbf{V}$ & $\mathbf{T i}$ \\
\hline$<\% 0.08$ & $<\% 0.25$ & $<\% 0.05$ & $<\% 0.2$ & $\% 5.5-6.67$ & $\% 3.5-4.5$ & Kalan \\
\hline
\end{tabular}

Çalışmada Ti6Al4V alaşımı kaplamasız WC takımla kesilmiştir. Deneylerde üç farklı kesme hızı kullanılmış olup diğer kesme parametreleri Tablo 2 'de özetlenmiştir.

Şekil 2 kesme testleri için tasarlanan deney kurulumunu göstermektedir. Deney sırasında kesme sıcaklığı FLIR SC325 marka termal kamera yardımıyla ölçülmüştür. Termal kamera ile ölçümlerde yaşanan önemli problemlerden biri kesme bölgesinin görülmesi problemidir. Bu amaçla Şekil 2'de görülen kamera tutucu tasarlanmıștır. Bu tutucu termal kamerayı tutmakta ve kesme sırasında kameranın takım ile birlikte hareketine izin vermektedir. Böylelikle kesme bölgesi tüm kesim boyunca izlenebilmektedir. 
Tablo 2. Kesme deneylerinde kullanılan parametreler

\begin{tabular}{|c|c|c|c|c|}
\hline $\begin{array}{c}\text { V } \\
(\mathbf{m} / \mathbf{d a k})\end{array}$ & $\mathbf{f} \mathbf{( m m / d e v )}$ & $\begin{array}{c}\text { Paso } \\
(\mathbf{m m})\end{array}$ & $\begin{array}{c}\boldsymbol{\alpha} \\
\mathbf{(} \mathbf{)}\end{array}$ & Takım \\
\hline 10 & 0.1 & 0.2 & 5 & $\begin{array}{c}\text { Kaplamasız } \\
\text { WC }\end{array}$ \\
\hline 20 & 0.1 & 0.2 & 5 & $\begin{array}{c}\text { Kaplamasız } \\
\text { WC }\end{array}$ \\
\hline 40 & 0.1 & 0.2 & 5 & $\begin{array}{c}\text { Kaplamasız } \\
\text { WC }\end{array}$ \\
\hline
\end{tabular}

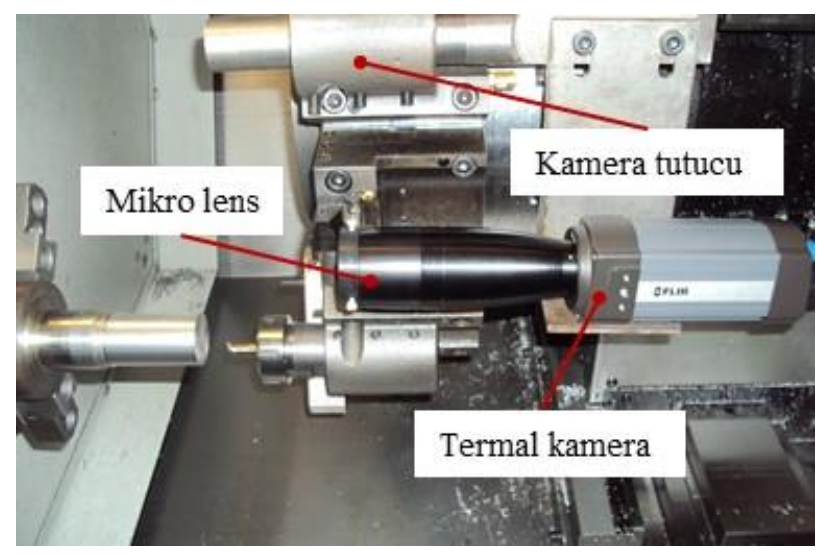

Şekil 2. Sıcaklık ölçümü için deney kurulumu

Talaşlı imalatta kesme işlemi çok küçük bir alanda gerçekleşmektedir. Bu küçük alanın net bir şekilde görülebilmesi için termal kameraya Şekil 2' de görüldüğü gibi bir mikro lens ilave edilmiştir. Bu lensin odak uzaklağı yaklaşık $10 \mathrm{~mm}$ olduğundan kamera kesici takıma bu mesafe kadar yaklaştırılmıştır. Bu yakınlık mikro lens için bir tehlike oluşturduğundan, mikro lense Şekil 3 'te görüldüğü gibi koruyucu bir kapak eklenmiştir. Bu kapağın ortasında ise $\mathrm{ZnSe}$ cam malzemesi bulunmaktadır. Bu malzemenin önemi, termal kamera ile ölçümlerde kullanılan kızılötesi ışınları \% 99 oranında geçirmesidir; böylelikle orijinal kamera lensi korunurken ölçümde yaşanacak hataların önüne geçilmesi planlanmıştır.

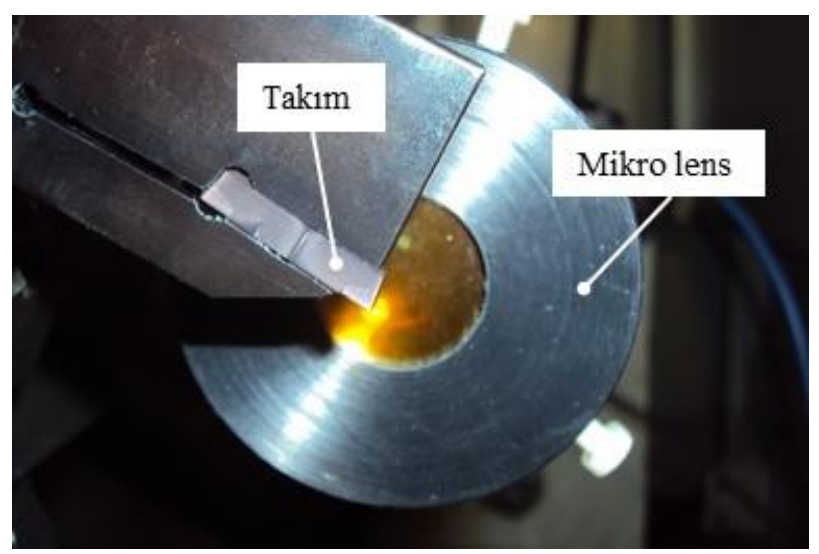

Şekil 3. Takım ve mikro lens

Yukarıda anlatıldı̆̆ı üzere tasarlanan deney kurulumu
Mori Seiki NL 1500 torna tezgâhına bağlanmış ve Tablo 2'de verilen kesme parametrelerinde testler gerçekleștirilmiştir. Şekil 4'te bu testler sırasında ölçülen kesme sıcaklıklarına ilişkin örnek bir görsel sunulmuştur. $\mathrm{Bu}$ görsel termal kameraya ait ThermaCam yazılımı ile elde edilmiştir.

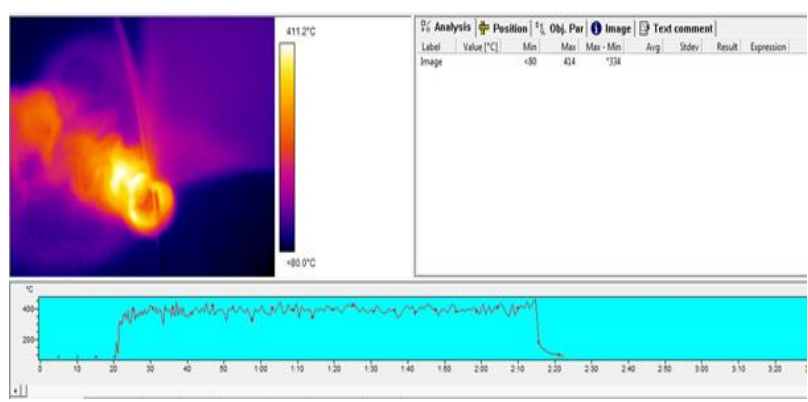

Şekil 4. ThermaCam yazılımından kesme anına ait alınan görüntü

\subsection{Yayma Katsayısı Kalibrasyonu}

Termal kamera ile ölçüm yöntemi araştırıldığında bu konudaki en büyük belirsizliğin ölçüm yüzeyinin bir karakteristiği olan yayma katsayısı değeri olduğu görülecektir. Termal kamera ışınım prensiplerine göre çalışmaktadır; buna göre bir yüzeyin ışınım yayma gücü şu şekilde ifade edilir:

$$
q=\varepsilon \sigma T^{4}
$$

Burada q isı akısı, $\sigma$ Stefan-Boltzman sabiti, $\varepsilon$ ilgilenilen yüzeyin yayma katsayısı değeri, $\mathrm{T}$ ise sıcaklı̆̆ıdır. Dolayısıyla bir yüzeyin sıcaklığının belirlenebilmesi için yayma katsayısının bilinmesi gerekir. $\mathrm{Bu}$ amaçla Ti6Al4V parçasının yayma katsayısı değerinin belirlenebilmesi için bir deney düzeneği tasarlanmış ve böylelikle yayma katsayısı farklı sıcaklıklar için kalibre edilmiştir.

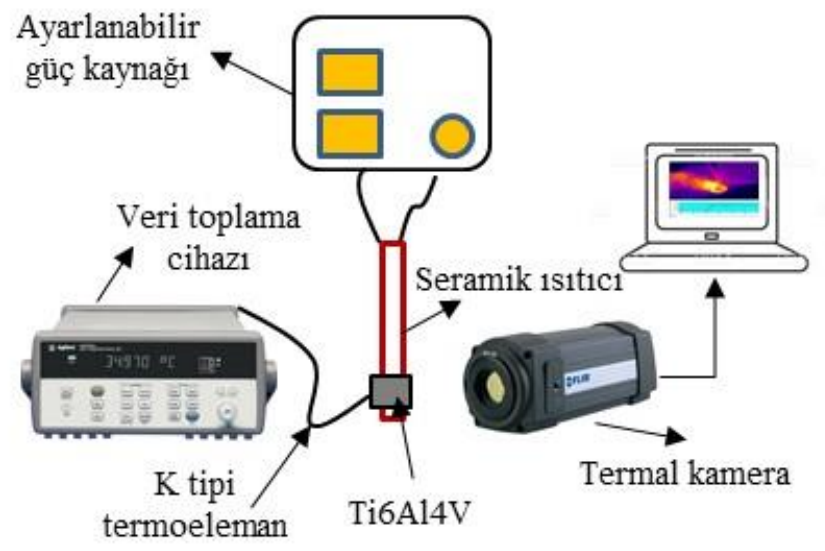

Şekil 5. ThermaCam yazılımından alınan görüntü

Şekil 5' te yayma katsayısının kalibrasyonu için geliştirilen deney düzeneği görülmektedir. $\mathrm{Bu}$ düzenekte fișek tipi adı verilen seramik yüzeyli ısıtıcı kullanılmıştır. Ti6Al4V işparçası ise bir yüzük şeklinde 
hazırlanıp bu fișek ısıtıcıya Şekil 5'te görüldüğü gibi geçirilmiştir. Buradaki amaç radyal simetrik bir şekilde parçayı ısıtmak ve böylelikle parçanın yüzeyinde aynı sıcaklıkları elde etmektir. Sonrasında parçanın yüzeyinde bir noktasına K tipi termoelaman bağlanmıș ve böylece sıcaklıklar takip edilmiștir. Parçanın yüzeyinde bulunan bir diğer noktası ise termal kamera ile gözlemlenmiştir. Ayarlanabilir bir güç kaynağı ile fişek ısıtıcının gücü değiştirilmiş ve böylelikle parça yüzeyinde değişik sıcaklıkların elde edilmesi sağlanmıştır. Son olarak termoeleman ile elde edilen sıcaklıklar ve termal kamera ile okunan sıcaklıklar birbiri ile eşleşecek şekilde yayma katsayısı değeri değiştirilmiştir. Bu şekilde elde edilen yayma katsayısı değerleri sıcaklığın bir fonksiyonu olacak şekilde Tablo 3'te verilmiştir.

Tablo 3. Yayma katsayısı kalibrasyonu

\begin{tabular}{|c|c|}
\hline Sicaklık $\left.\mathbf{~}^{\circ} \mathbf{C}\right)$ & Yayma katsayısı \\
\hline 100 & 0.345 \\
\hline 150 & 0.279 \\
\hline 200 & 0.246 \\
\hline 250 & 0.233 \\
\hline 300 & 0.227 \\
\hline
\end{tabular}

Tablo 3'teki değerler Şekil 6'da grafik halinde de verilmiștir. Şekil 6'dan da görüleceği üzere yayma katsayısı sıcaklık arttıkça belirli bir değere yakınsamaktadır. Talaşlı imalatta sıcaklıklar genellikle burada verilen değerlerin üzerinde olduğundan çalışmada Ti6Al4V için yayma katsayısı değeri 0.22 olarak alınmıştır. Bu değer ThermaCam yazılımına girilerek ilgili sıcaklık değerleri yorumlanmıştır.

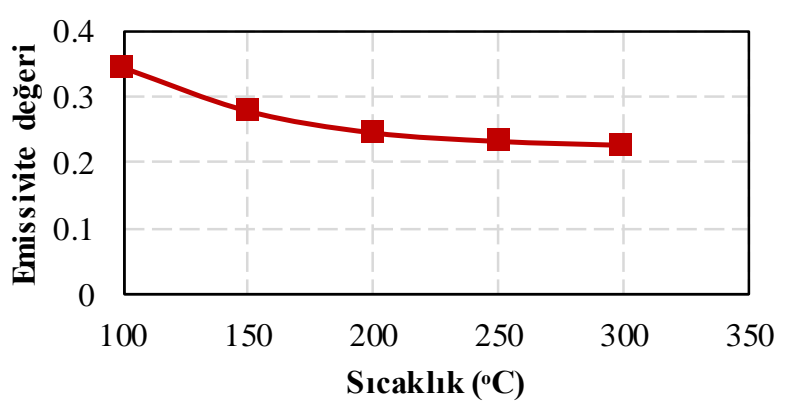

Şekil 6. Yayma katsayısının sıcaklıkla değişimi

\section{Sonlu Elemanlar Modeli}

Çalışmanın diğer aşamasında kesme sırasında elde edilen sıcaklıklar sonlu elemanlar yöntemi ile tahmin edilmiş ve bu tahmin edilen sıcaklıklar deneysel olarak elde edilen sonuçlarla karşılaştırılmıştır.

Çalışmada sonlu elemanlar metodu ile modelleme için DEFORM 2D yazılımı tercih edilmiştir. Bu yazılım sadece talaşlı imalat operasyonlarının modellenmesi için değil plastik deformasyona dayalı dövme veya haddeleme gibi diğer şekillendirme işlemlerinin de modellenmesinde tercih edilen bir yazılımdır. $\mathrm{Bu}$ modelleme sırasında malzemenin çeșitli sıcaklıklar, birim şekil değişimleri ve birim şekil değişim hızları altındaki akma dayanımını veren bünye denklemlerinden faydalanılır. Çalışmada, bu amaçla Johnson-Cook malzeme modelinden faydalanılmıștır (Johnson ve Cook, 1985). Bu model Denklem 2'de verilmiştir. Burada $\tau$, malzemenin akma dayanımı, $\gamma_{\text {, }}$ birim şekil değişimi, $\dot{\gamma}$, birim şekil değişim hızı, $T$ sıcaklık, $T_{m}$, malzemenin erime sıcaklığı, $T_{r}$ ise referans sicaklıktır son olarak $A, B, n, C, v$ ise Johnson-Cook sabitleri olarak bilinirler.

$$
\tau=\frac{1}{\sqrt{3}}\left[A+B\left(\frac{\gamma}{\sqrt{3}}\right)^{n}\right]\left[1+C \ln \left(\frac{\dot{\gamma}}{\dot{\gamma}_{0}}\right)\right]\left[1-\left(\frac{T-T_{r}}{T_{m}-T_{r}}\right)^{v}\right]
$$

Ti6Al4V malzemeye ait Johnson-Cook sabitleri Tablo 4 'te verilmiştir.

Tablo 4. Ti6Al4V için Johnson-Cook sabitleri

\begin{tabular}{|c|c|c|c|c|}
\hline $\boldsymbol{A}$ (MPa) & $\boldsymbol{B}(\mathbf{M P a})$ & $\boldsymbol{n}$ & $\boldsymbol{C}$ & $\boldsymbol{v}$ \\
\hline 968 & 380 & 0.421 & 0.0197 & 0.577 \\
\hline
\end{tabular}

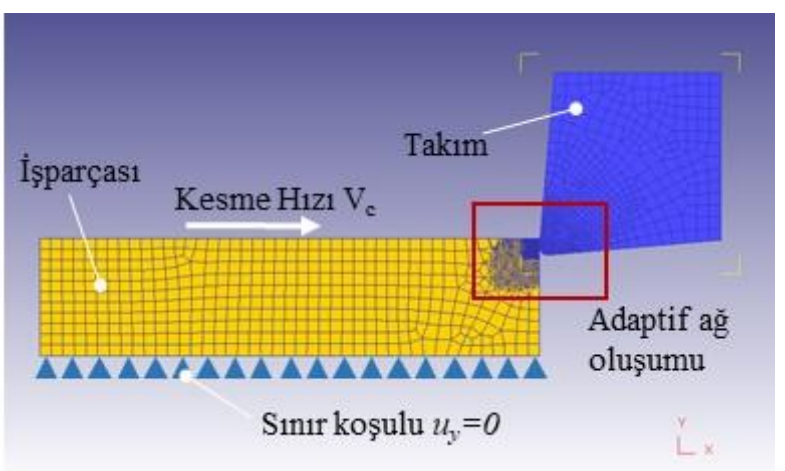

Şekil 7. Sonlu elemanlar modeli için sınır koşulları

Şekil 7 'de Ti6Al4V malzemenin talaşlı imalatının simülasyonu için DEFORM 2D yazılımında kurulan 2 boyutlu model görülmektedir. Talaşlı imalatta plastik deformasyon (kesme olayı) çok küçük bir alanda gerçekleşmektedir. Bu nedenle Şekil 7'den görüleceği gibi bu alanda adaptif ağ oluşumundan faydalanılmıștır. $\mathrm{Bu}$ sayede bu bölge daha ince elemanlarla temsil edilmiş ve sonuçların doğruluğu arttırılmıştır. Sınır koşulu olarak y ekseninde parça hareketi kısıtlanırken x ekseninde parça hareketi için kesme hızı tanımlanmıștır. Ayrıca işparçası yazılımda plastik olarak tanımlanırken, takım ise rijit olarak belirtilmiştir. 


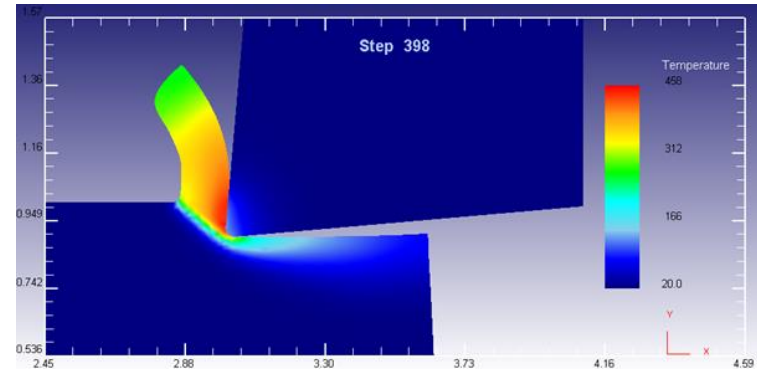

Şekil 8. Sonlu elemanlar modelinde talaş oluşumu

Şekil 8'de sonlu elemanlar simülasyonu sırasında elde edilen talaş oluşumu gösterilmiștir. Şekil 8 ayrıca oluşan sıcaklıkların kesme bölgesindeki dağılımını göstermektedir. Yazılımda kesme kuvvetleri, birim şekil değişimleri, gerilmeler gibi farklı süreç çıktıları analiz edilebilmektedir. Ancak bu çalışmanın konusunu kesme sıcaklıkları oluşturduğundan Şekil 8'de yalnızca sıcaklık sonuçları verilmiştir.

Çalışmanın önemli bir diğer amacı da elde edilen deneysel ve simülasyon sonuçlarının karşılaştırılmasıdır. Bu karşılaştırma için kesme bölgesindeki en yüksek sıcaklıklar kullanılmıștır; çünkü hem çalışmada kullanılan termal kamera yazılımı ThermaCam hem de modelleme için kullanılan DEFORM 2D yazılımı kesme bölgesindeki en yüksek sıcaklıkların analizine imkân vermektedir. Tablo 5 ve Şekil 9 bu karşılaştırma sonuçlarını vermektedir. $\mathrm{Bu}$ karşılaştırmalardan da görüleceği gibi deneysel sonuçlar ve modelleme sonuçları birbirine oldukça yakın değerler vermektedir. Ayrıca kesme hızı ile sıcaklıkların arttığı da net bir şekilde hem deneysel hem de teorik olarak ortaya konulmuştur.

Tablo 5. Elde edilen en yüksek sıcaklık değerleri

\begin{tabular}{|c|c|c|}
\hline $\mathbf{V}(\mathbf{m} / \mathbf{d a k})$ & $\begin{array}{c}\text { Deneysel } \\
\mathbf{T}\left({ }^{\mathbf{0}} \mathbf{C}\right)\end{array}$ & $\begin{array}{c}\text { Sonlu Elemanlar } \\
\mathbf{T}\left({ }^{\mathbf{o}} \mathbf{C}\right)\end{array}$ \\
\hline 10 & 393.72 & 394 \\
\hline 20 & 494.87 & 458 \\
\hline 40 & 568.98 & 529 \\
\hline
\end{tabular}

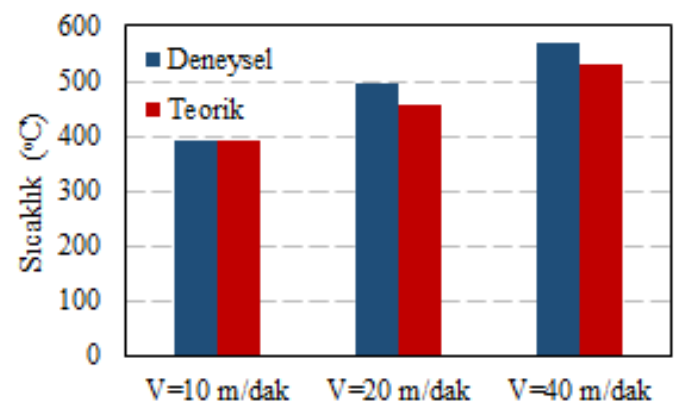

Şekil 9. Deneysel ve teorik sonuçların karşılaştırılması

\section{Sonuç ve Tartışma}

Kesme sıcaklıkları, talaşlı imalatta karşılaşılan en önemli problemlerin başında gelmektedir. Bunun nedeni; bu sıcaklıkların, parça bütünlüğü, takım aşınması gibi işlem maliyetini doğrudan etkileyen süreç çıktıları üzerindeki etkiledir. Bu amaçla bu çalışmada bu sıcaklıkların ölçülmesi ve modellenmesi için bazı yaklaşımlar ortaya konulmuştur.

Kesme sırasında oluşan sıcaklıkların ölçülmesi oldukça zahmetli bir iştir, termal kameralar bu zahmetli iş için en gelişmiş araçlar olarak öne çıkmaktadırlar; ancak bu gelişmiş teknolojilerin kesme tezgâhları ile bütünleşmesi için hala araştırmaya ihtiyaç vardır. Bu amaçla, bu çalışmada ilk olarak elimizde var olan termal kameranın torna tezgâhına uygun bir şekilde yerleştirilmesi için bir deney düzeneği tasarımı yapılarak, torna tezgâhına monte edilmiștir. Ayarlanabilen bu deney düzeneği ile görüntü netliği kesme sırasında da korunmuştur.

Termal kamera teknolojik olarak güç bir araçtır; ancak ölçüm sırasında kullanılan bazı parametrelerin bilinmesi gerekir bunların başında incelenen yüzeyin yayma katsayısı değeri gelmektedir. Literatürde termal kamera ile yapılan araştırmalarda bu değerin ortalama bir değer olarak belirlendiği gözlemlenmiștir. Bu belirsizliği giderebilmek adına yeni bir deney düzeneği tasarlanarak Ti6Al4V alaşımının yayma katsayısı için bir kalibrasyon sistemi tasarlanmış ve güzel sonuçlar elde edilmiştir. Elde edilen sonuçlar termal kamera ile ölçümde kullanılmıștır.

Deneysel çalıșmanın yanında, bir diğer güçlü araç ise modellemedir. Günümüzde bilgisayar teknolojisinin gelişmesi ile birlikte artık üretim mühendisliği de sanal dünyaya geçiş yapmaktadır. Buradaki en önemli amaç ise daha üretim yapılmadan süreç çıktılarının belirlenebilmesidir. Bu amaçla çalışmada son olarak sonlu elemanlar yönteminden faydalanılmıştır. Ticari bir yazılım olan DEFORM 2D'de simülasyon gerçekleştirilmiş ve bu sonuçlar deneysel olarak elde edilen değerlerle karşılaştırılmıştır. Sonuçların birbirine yakınlığı hem kurulan modelin hem de elde edilen yayma katsayısı değerinin gerçekçi olduğunu göstermektedir.

Sonuçlar ayrıca açıç̧a kesme hızının artmasıyla sıcaklı̆̆ın arttığını göstermektedir. Bu bilgi özellikle kesme parametrelerinin seçimi konusunda yol gösterici olacaktır.

Bu çalışmada elde edilen sonuçlar gelecek çalışmalarla arttırılabilir. Özellikle diğer malzemelerin de yayma katsayısı değerlerinin belirlenmesinde bu çalışmada sunulan düzenek kullanılabilir. Ayrıca geliştirilen deney düzeneği diğer takım tezgâhlarına da uyarlanarak farklı talaşlı imalat yöntemlerinde kesme sıcaklıklarının ölçümü gerçekleştirilebilir. 


\section{Teşekkür}

$\mathrm{Bu}$ çalışmaya yardımlarından dolayı Sabancı Üniversitesi öğretim üyesi Prof. Dr. Erhan Budak ve İTÜ öğretim üyesi Prof. Dr. Mustafa Bakkal'a teşekkür ederim.

\section{Conflict of Interest / Çıkar Çatışması}

Yazar tarafından herhangi bir çıkar çatışması beyan edilmemiştir.

No conflict of interest was declared by the author.

\section{Kaynaklar}

Abukhshim, N.A., Mativenga, P.T., Sheikh, M. A., 2006. Heat generation and temperature prediction in metal cutting: A review and implications for high speed machining. International Journal of Machine Tools and Manufacture, 46(7-8), 782-800.

Armendia, M., Garay, A., Villar, A., Davies, M.A., Arrazola, P.J., 2010. High bandwidth temperature measurement in interrupted cutting of difficult to machine materials. CIRP annals, 59(1), 97-100.

Da Silva, M.B., Wallbank, J., 1999. Cutting temperature: prediction and measurement methods-a review. Journal of materials processing technology, 88(13), 195-202.

Davies, M.A., Cooke, A.L., Larsen, E.R., 2005. High bandwidth thermal microscopy of machining AISI 1045 steel. CIRP Annals-Manufacturing Technology, 54(1), 63-66.

Ezugwu, E.O., Wang, Z.M., 1997. Titanium alloys and their machinability - a review. Journal of materials processing technology, 68(3), 262-274.

Hahn, R.S., 1951. On the temperature developed at the shear plane in the metalcutting process. Journal of Applied Mechanics-Transactions of the ASME, Vol. 18, No. 3, pp. 323-323.

Jaeger, J.C., 1942. Moving sources of heat and the temperature of sliding contacts. In Proc. Roy. Soc., NSW Vol. 176, p. 203.

Jiang, F., Liu, Z., Wan, Y., Shi, Z., 2013. Analytical modeling and experimental investigation of tool and workpiece temperatures for interrupted cutting 1045 steel by inverse heat conduction method. Journal of Materials Processing Technology, 213(6), 887-894.

Johnson, G.R., Cook, W.H., 1985. Fracture characteristics of three metals subjected to various strains, strain rates, temperatures and pressures. Engineering fracture mechanics, 21(1), 31-48.
Leshock, C. E., Shin, Y.C., 1997. Investigation on cutting temperature in turning by a tool-work thermocouple technique. Journal of manufacturing science and engineering, 119(4A), 502-508.

Longbottom, J.M., Lanham, J.D., 2005. Cutting temperature measurement while machining-a review. Aircraft Engineering and Aerospace Technology, 77(2), 122-130.

Ozel, T., Altan, T., 2000. Process simulation using finite element method-prediction of cutting forces, tool stresses and temperatures in high-speed flat end milling. International Journal of Machine Tools and Manufacture, 40(5), 713-738.

Shaw, M. C., Cookson, J.O., 1984. Metal cutting principles (pp. 183-201). Oxford: Clarendon press.

Stephenson, D.A., Ali, A. 1992. Tool temperatures in interrupted metal cutting. Journal of Engineering for Industry, 114(2), 127-136.

Stephenson, D.A., 1993. Tool-work thermocouple temperature measurements-theory and implementation issues. Journal of Engineering for industry, 115(4), 432-437.

Sullivan, D., Cotterell, M., 2001. Temperature measurement in single point turning. Journal of Materials Processing Technology, 118(1-3), 301308.

Trent, E.M., Wright, P.K., 2000. Metal cutting. Butterworth-Heinemann. 